\title{
HISTÓRIA E FILOSOFIA DA HISTÓRIA NA OBRA DO JOVEM FRIEDRICH SCHLEGEL
}

\author{
Izabela Maria Furtado Kestler* \\ izabela@alternex.com.br
}

RESUMO Este artigo apresenta e comenta dois textos do jovem Friedrich Schlegel, Vom Wert des Studiums der Griechen und Römer (Sobre o valor do estudo dos gregos e romanos), de 1795/1796, e Über das Studium der griechischen Poesie (Sobre o estudo da poesia grega), de 1795, escritos antes de sua ida para Jena, em 1796, nos quais o autor elabora uma teoria original sobre a história e a filosofia da história.

Palavras-chave Filosofia da história; Iluminismo; Antigo; Moderno.

ABSTRACT This article introduces and comments two texts written by Friedrich Schlegel in his youth, before he moved to Jena in 1796: Vom Wert des Studiums der Griechen und Römer (On the value of the study of Greeks and Romans) of 1795/1796 and Über das Studium der griechischen Poesie (On the study of Greek poetry) of 1795. In these texts the author develops an original theory concerning history and the philosophy of history.

Keywords Philosophy of history; Enlightenment; Ancient; Modern.

* Professora do Departamento de Letras Anglo-Germânicas da Faculdade de Letras da UFRJ. Artigo recebido em fevereiro de 2007 e aprovado em março de 2008. 


\section{Introdução}

Os dois textos, inéditos no Brasil, ${ }^{1}$ inscrevem-se no contexto mais amplo da filosofia da história iluminista por tratarem da questão da perfectibilidade da história da humanidade. Tal questão era praticamente consenso entre os pensadores do Iluminismo. Mas, enquanto em pensadores como Condorcet, ${ }^{2} \mathrm{e}$ antes dele Leibniz, não havia dúvidas quanto à capacidade de aperfeiçoamento ilimitado do homem, a idéia da perfectibilidade em Kant, Herder e Fichte de um modo geral tem nuances pouco otimistas. Nesses primeiros textos, Schlegel é influenciado fortemente tanto pela filosofia sistemática de Fichte quanto pelo historismo de Herder. Mas são as idéias de Fichte, expostas em suas Vorlesungen über die Bestimmungen des Gelehrten (Lições sobre a vocação do sábio), de 1794, sobre a perfectibilidade como fim inantingível (unendliche Perfektibilität) no contexto da aproximação infinita (endlose Annäherung) que formam o núcleo central das concepções de história e história da filosofia nas obras do jovem Schlegel. ${ }^{3}$ Além disso, a variante alemã da idéia de perfectibilidade é determinada pelo antagonismo acentuado, tanto na visão de Kant quanto na de Schiller, entre liberdade e natureza, segundo a qual no início da história da formação humana teria ocorrido a supremacia da natureza sobre a liberdade e o percurso do aperfeiçoamento se manifestaria portanto como uma ascensão e superação dos grilhões da natureza e da menoridade (Unmündigkeit). ${ }^{4}$

Uma segunda característica relevante nesses textos de Schlegel diz respeito à referencialidade ao modelo de perfeição da Antigüidade clássica grega, específica da reflexão estética no âmbito alemão. Tal modelo, defendido veementemente por Johann Joachim Winckelmann em suas obras da segunda

1 A tradução do primeiro texto já está pronta, e em fase de revisão. Já iniciei a tradução do segundo texto, mais longo, com o objetivo de publicar ambos futuramente.

2 Ver Condorcet, Esquisse d'un tableau historique des progrès de l'espirit humain, de 1794. Schlegel escreve uma resenha crítica sobre esse tratado, intitulada "Über Condorcet: Esquisse d'un Tableau des Progrès de l'Esprit Humain", em 1795. Essa resenha foi publicada no mesmo ano no Philosophisches Journal einer Gesellschaft Teutscher Gelehrtern, editado por Friedrich Niethammer.

3 "Submeter a si tudo o que é desprovido de razão, dominá-lo livremente e segundo a sua própria lei, é o derradeiro fim último do homem; fim último que é totalmente inacessível e deve permanecer eternamente inacessível, se o homem não houver de deixar de ser homem e tornar-se Deus. O conceito de homem implica que o seu postremo fito é inatingível, que o seu caminho para o mesmo deve ser infinito. Por conseguinte, o destino do homem não é atingir semelhante meta. Mas ele pode e deve aproximar-se sempre mais desse fito e, por isso, acercar-se indefinidamente desta meta constitui a sua verdadeira vocação como homem, isto é, como ser racional mas finito, sensível mas livre" (FICHTE, Lições sobre a vocação do sábio/Reivindicação da liberdade de pensamento, p. 27-28). Ver também: FRANK. „Unendliche Annäherung". Die Anfänge der philosophischen Frühromantik.

4 BEHLER. „Einleitung: Friedrich Schlegels Studium-Aufsatz und der Ursprung der romantischen Literaturtheorie", p. 109. 
metade do século XVIII, ${ }^{5}$ tem importância e influência fundamentais em praticamente toda a reflexão de inúmeros autores alemães posteriores, sobretudo no âmbito da querela dos Antigos e dos Modernos. A supremacia do paradigma de excelência da Antigüidade grega em confronto com a Modernidade é indubitavelmente um ponto fulcral da reflexão estética de autores e poetas no final do século XVIII, os quais vislumbravam na Grécia antiga uma utopia perfeita à qual se deveria retornar no futuro. Pois: "O único meio de nos tornarmos grandes e, se possível, inimitáveis, é imitar os gregos". ${ }^{6}$

Com o intuito de responder à questão levantada por Herder em seus Fragmente über die neuere deutsche Literatur (Fragmentos sobre a mais recente literatura alemã), de 1767, Schlegel pretende em sua juventude realizar no campo da poesia grega o que Winckelmann realizou no tocante à arte grega. Herder se perguntara:

Mas onde está então um Winckelmann alemão, que nos descortine tão bem o templo da sabedoria e da arte poética gregas quanto mostrou aos artistas de longe o segredo dos gregos? Um Winckelmann com a intenção de abordar a arte só poderia florescer em Roma; mas um Winckelmann com o objetivo de nos ensinar a poesia grega só pode surgir na Alemanha. ${ }^{7}$

O problema que Schlegel tem que resolver teoricamente é como conciliar a concepção de perfectibilidade com sua crença arraigada na perfeição atingida na Antigüidade clássica.

\section{Análise e apresentação das obras do jovem Friedrich Schlegel}

Em sua pequena obra Vom Wert des Studiums der Griechen und Römer, de 1795/1796, Schlegel apresenta concisamente suas próprias concepções sobre história e filosofia da história. Para Schlegel, história é sempre história universal, história da humanidade como um todo. Há também a reafirmação do paradigma da história como ciência da totalidade e da unicidade.

A história deve ser lembrada sempre da exigência necessária da unidade, da concordância futura com a ciência pura [...] Quão mais rica for a multiplicidade, mais decididamente se torna a necessidade de uma unidade, quanto mais as diferentes

5 As obras são as seguintes: Gedanken über die Nachahmung der griechischen Werke in der Malerei und in der Bildhauerkunst (Reflexões sobre a imitação das obras gregas na pintura e na escultura), de 1755, e Geschichte der Kunst des Altertums (História da arte da antigüidade), de 1764.

6 WINCKELMANN. Reflexões sobre a arte antiga, p. 39-40.

7 HERDER. Fragmente über die neuere deutsche Literatur. In: Herders sämtliche Werke. Org. por Bernhard Suphan, p. 293 et seq. 
formas de conexão tiverem se desenvolvido e se encontrarem em disputa, mais urgente se torna a necessidade de uma completude. ${ }^{8}$

Em passagem posterior, Schlegel explicita o que é a história da humanidade, a qual

não pode ser outra coisa senão [...] a história completa da espécie humana, que teria uma ordem sistemática, um fundamento científico e um sentido válido de forma geral. O objeto desta história não são somente as ações e mudanças públicas de um povo determinado, mas sim costumes e época, arte e estado, crenças e ciência, em resumo todos os atos, qualidades e condições puramente humanos: formação humana, ou a luta da liberdade contra a natureza. ${ }^{9}$

Em outras palavras, isto significa que a concepção de história para Schlegel se encontra não só dentro dos parâmetros do Iluminismo, mas que deve ser considerada sob o ponto de vista de uma antropologia cultural, ou melhor, de uma formação (Bildung) do gênero humano. Mais adiante, ele lamenta o fato de que

falta tanto à formação moderna a simetria, o equilíbrio, a concatenação, a concordância e a completude, as forças pensante e atuante estão separadas por um abismo tão intransponível, os limites e direitos da razão e da experiência estão tão indeterminados, a humanidade tão dilacerada e portanto os conceitos sobre o valor das coisas tão confusos, que esta apologia da história não parece redundante. Quase se poderia dizer que a história merece o desprezo generalizado e ruidoso dos pensadores puros, pois existe uma história da natureza cientificamente sistematizada dos animais e plantas, mas não há nenhuma história da espécie humana, a qual mereceria ser chamada de científica. ${ }^{10}$

Completando esta idéia, Schlegel afirma a seguir que o homem só se apropria da experiência através da ordem, da sistematização, cujos degraus encontramos nos gregos, os quais embora tenham escalado os primeiros degraus não alcançaram os superiores. A intenção de Schlegel se torna mais clara ainda quando ele afirma como é difícil a tarefa de se encontrar uma unidade incondicional, um fio condutor da disposição a priori para a história universal, a qual satisfaria tanto a razão teórica quanto a prática, sem insultar os direitos do entendimento nem violentar os fatos da experiência. Em sua argumentação, Schlegel prossegue traçando um panorama crítico das obras de sua época neste campo. Em primeiro lugar, comenta elogiosamente a obra de 
Herder sobre a filosofia da história, ${ }^{11}$ assinalando no entanto que falta a esta não só um fio condutor, que unifique as suas partes, mas também que ela não é um todo completo em si mesmo. A obra de Kant, Idee zu einer allgemeinen Geschichte in weltbürgerlicher Absicht (Idéia de uma história universal sob um ponto de vista cosmopolita), abordada a seguir, é criticada pelo fato de esta querer provar a impossibilidade de uma história da humanidade. Além de Kant, Schlegel critica acidamente o ceticismo de outros iluministas, como Voltaire e Hume, que não enxergavam nenhum sentido na história nem valor algum no ser humano.

Depois destas críticas, Schlegel desenvolve e expõe então suas idéias sobre a história e a filosofia da história. A idéia de uma relação de ação recíproca (Wechselwirkung) entre liberdade e natureza, tomada de empréstimo a Fichte, ${ }^{12}$ irá a seguir alicerçar a argumentação de Schlegel no sentido de que tem que haver uma história também com leis necessárias.

Se a liberdade e a natureza cada uma por si estão submetidas a leis, se há uma liberdade (pois isto é o que negam os adeptos coerentes da assistematicidade e da ausência de leis na história: este é o fundamento de suas opiniões), se as idéias do ser humano são um todo conexo - um sistema, então a ação recíproca entre liberdade e natureza, a história estão submetidas a leis necessárias e imutáveis. Se há uma tal ação recíproca, há história, e por conseguinte tem que haver um sistema de leis necessárias a priori. Se supusermos como fato da experiência ou pelo menos como possibilidade, que a liberdade no homem singular ou mesmo na massa de povos singulares tenha tido ou poderia ter tido um peso preponderante, que tenha havido homens e povos educados (gebildete), então o único sistema da história que poderia satisfazer plenamente a razão teórica, sem insultar os direitos do entendimento e da experiência, é o sistema cíclico (System des Kreislaufs). Se ponderarmos que a natureza em tempo algum é aniquilada pela liberdade, que o infinito em tempo algum poderia se tornar real, então o único sistema da história, o qual satisfaria a razão prática, sem ofender o entendimento, é o sistema da progressividade infinita (System der unendlichen Fortschreitung). Não poderiam talvez estes dois sistemas em linha reta e opostos ser unificados e desta forma não poderiam ser satisfeitas a razão prática e a teórica ao mesmo tempo? [...] a história antiga e a moderna seriam então dois todos diversos, que poderiam se basear em leis completamente diferentes...? ${ }^{13}$

11 Trata-se aqui das Ideen zur Philosophie der Geschichte der Menschheit (Idéias sobre a filosofia da história da humanidade), concluída em 1791.

12 Schiller em seu tratado A educação estética do homem numa série de cartas também emprega o conceito fichteano de ação recíproca para fundamentar a superação da oposição entre o impulso formal e o impulso sensível, os quais através da mencionada ação recíproca se transmutam em impulso lúdico. Ver: KESTLER. Friedrich Schiller e a fundação do cânone da modernidade. Forum Deutsch. Revista Brasileira de Estudos Germânicos, p. 109-110.

13 SCHLEGEL. Vom Wert des Studiums der Griechen und Römer (1795-1796), p. 36. 
Completando este panorama de duas histórias diferentes, Schlegel apresenta então a idéia de que a ação recíproca entre liberdade e natureza, a dupla forma de formação (Bildung), ou seja, de história, seria possível. Esta dupla forma de formação é explicitada então da seguinte maneira: correspondente ao sistema cíclico teria havido uma formação natural (natürliche), e ao sistema de progressividade infinita corresponderia uma formação artificial (künstliche), sendo que a formação natural, a história cíclica, é anterior à formação artificial, à história como progressividade infinita. A história cíclica é a história dos gregos e romanos, considerada por Schlegel como a metade mais importante da história da humanidade. Apesar da relevância com que ele enfatiza o estudo dos antigos, há em seu texto uma decidida opção pelos modernos.

A maioria dos amigos dos antigos paga caro por seus conhecimentos da antigüidade com a ignorância completa e o desprezo cego do novo: eles vêm em sua época nada além das ruínas de uma humanidade destruída, a vida deles não é mais que uma elegia diante da urna do passado. ${ }^{14}$

Prosseguindo em sua argumentação, Schlegel assinala que a formação entre os gregos e romanos constituía uma totalidade e que

alcançou um máximo, não o máximo absoluto, que é o objetivo da história moderna, o qual não pode ocorrer em nenhuma época e em nenhuma história, mas sim o máximo, que era possível no sistema cíclico, o máximo de formação natural, ou seja um máximo relativo. ${ }^{15}$

Além disso, o estudo dos gregos e romanos é de fundamental importância para os modernos e para a humanidade como um todo, porque, enquanto o belo e o bom continuarem sendo segredo de umas poucas almas nobres e não forem propriedade pública, a formação moderna permanece próxima demais de sua origem bárbara:

O arquétipo (Urbild) da humanidade no patamar superior da formação antiga é o único fundamento possível da formação moderna como um todo... ${ }^{16}$

E também:

a visão constante do arquétipo anterior a nós, o objetivo superior diante de nós, nos preservará do desânimo, nos ensinará, que não é nossa destinação viver como

14 SCHLEGEL. Vom Wert des Studiums der Griechen und Römer (1795-1796), p. 32.

15 SCHLEGEL. Vom Wert des Studiums der Griechen und Römer (1795-1796), p. 38.

16 SCHLEGEL. Vom Wert des Studiums der Griechen und Römer (1795-1796), p. 41. 
mendigos das esmolas do mundo passado, nem como servos no trabalho braçal para o mundo futuro, pois como qualquer homem singular não existe em função da espécie, mas sim como finalidade em si mesmo, então também uma época não pode perder através da postergação condicional seus direitos inalienáveis por isonomia incondicional. ${ }^{17}$

Aqui nesta passagem Schlegel recupera a idéia de Herder de isonomia, ou seja, de igualdade de direitos, de todas as épocas, pois em sua visão de história moldada pelo princípio da perfectibilidade infinita nenhuma época teria alcançado o Absoluto. ${ }^{18}$ Por outro lado, Schlegel não aceita a idéia mais cara a Herder, ou seja, a valorização de cada uma das épocas históricas através de suas manifestações poéticas e artísticas:

O método de considerar cada florescimento da arte, sem avaliação, somente segundo o local, o tempo e o tipo, levaria finalmente a nenhuma outra conclusão senão a de que tudo deveria ser o que é e o que foi. ${ }^{19}$

Ainda no mesmo texto, Schlegel assinala qual teria sido a origem da história moderna, ou melhor, onde terminaria uma história, a cíclica (com início, desenvolvimento, apogeu, decadência e fim) e começaria a outra, a progressiva.

$\mathrm{O}$ antigo e o novo sistema se separam, se dissociam da forma mais clara, onde em lugar das religiões nacionais apareceu uma religião universal. ${ }^{20}$

Trata-se do Cristianismo, a religião universal que suplantou as religões locais e/ou nacionais. Mais adiante, Schlegel afirma também que a história antiga não terminou abruptamente com a instauração de uma religião universal e que as manifestações de decadência moral dos fins da história antiga ainda perdurariam até hoje. Por outro lado, as primeiras sementes da história moderna já estariam prefiguradas na filosofia racional de um Sócrates ou mais anteriormente até em Pitágoras, o primeiro a ousar estabelecer os costumes e o Estado em conformidade com as idéias da razão pura. Sobre isso, comenta Ernst Behler:

No campo da literatura, da filosofia e também no pensamento político, a questão quanto ao início da modernidade conduz a uma data surpreendentemente antiga.

17 SCHLEGEL. Vom Wert des Studiums der Griechen und Römer (1795-1796), p. 43.

18 BEHLER. ,Die Theorie der Kunst ist ihre Geschichte”: Herder und die Brüder Schlegel. In: BEHLER. Studien zur Romantik und zur idealistischen Philosophie, v. 2, p. 193.

19 SCHLEGEL. Herders Briefe zur Beförderung der Humanität (1796), p. 176.

20 SCHLEGEL. Vom Wert des Studiums der Griechen und Römer (1795-1796), p. 39. 
Schlegel não se esquivou em responder a esta questão, apontando na tragédia grega, como Nietzsche mais tarde em Eurípedes, o início da modernidade e a dissolução do mito através do racionalismo e do ceticismo. ${ }^{21}$

\section{Segundo Ernst Behler, a virada da história acontece para Schlegel quando} há uma transição da natureza para a liberdade.

Com isso manifesta-se ao mesmo tempo o conceito de formação (Bildungsbegriff) de Schlegel, o qual dá conteúdo e sentido ao processo histórico. Formação era para Schlegel não como para Herder "obra do destino", nem "resultado de milhares de causas atuantes", mas sim uma obra da liberdade dos homens, "luta renhida de vida ou morte com o poder terrível, de cujas garras ele nunca pode escapar." 22

Isto significa que a história em Schlegel tem como motor a eterna luta entre natureza e liberdade, ou seja, a luta entre as circunstâncias que condicionam interna e externamente o homem e a livre autodeterminação. Para resolver este dilema, Schlegel utiliza o conceito, já mencionado acima, de relação de ação recíproca (Wechselwirkung) entre natureza e liberdade.

Partindo destes princípios de filosofia da história, a trajetória da humanidade parece ser na visão do jovem Schlegel como uma luta de morte para se escapar da necessidade da natureza e conquistar gradualmente a autodeterminação em liberdade. Já se assinalou com razão, que esta filosofia da história centrada na autodeterminação progressiva da humanidade superou o pensamento de um Lessing, Herder e Kant, ainda com idéias latentes de um plano divino ou de uma providência, e que Schlegel mais radicalmente que estes pensadores concebia a história como obra da própria humanidade. $^{23}$

No texto abordado a seguir, Über das Studium der griechischen Poesie (Sobre o estudo da poesia grega), mais conhecido como Studium-Aufsatz, ${ }^{24}$

21 BEHLER. Einleitung: Friedrich Schlegels Studium-Aufsatz und der Ursprung der romantischen Literaturtheorie, p. 106.

22 BEHLER. Einleitung: Friedrich Schlegels Studium-Aufsatz und der Ursprung der romantischen Literaturtheorie, p. 107.

23 BEHLER. Einleitung: Friedrich Schlegels Studium-Aufsatz und der Ursprung der romantischen Literaturtheorie, p. 108.

24 Esse texto só foi publicado integralmente em 1797 como primeira parte do volume Die Griechen und Römer. Historische und kritische Versuche über das klassische Altertum, na cidade de Neustrelitz aos cuidados do editor Salomon Michaelis. Alguns capítulos, no entanto, foram publicados antecipadamente na revista Deutschland de Johann Friedrich Reichardt em 1796. O editor dessa revista, partidário da Revolução Francesa, opunha-se frontalmente às idéias preconizadas pela revista Horen de Friedrich Schiller. Isso explica em parte o fato de Schlegel ter sido antipatizado por Schiller desde o início de sua estada em Jena a partir de 1796. Vale lembrar também que o texto de Schlegel, embora tenha sido escrito no mesmo ano que o tratado de Schiller, Über naive und sentimentalische Dichtung (Poesia ingênua e sentimental), só veio a público integralmente depois da publicação do tratado de Schiller em sua revista Horen. 
verifica-se a transposição destas idéias de história e filosofia da história, sobretudo a questão da perfectibilidade infinita, para o campo da estética e da teoria poética. Esta obra inscreve-se, juntamente com o tratado Über naive und sentimentalische Dichtung (Poesia ingênua e sentimental) de Schiller, de 1795-1796, no contexto maior de uma resposta na Alemanha à célebre Querelle des anciens et des modernes. ${ }^{25}$

A arte é infinitamente perfectível e um máximo absoluto não é possível em seu desenvolvimento permanente: um máximo relativo, no entanto, um próximo fixo insuperável é possível. ${ }^{26}$

Este máximo relativo seria a poesia grega, entendida como o arquétipo da arte e do gosto. Em sua argumentação, Schlegel aplica o postulado da formação natural em correlação com a história cíclica, assinalando que a arte antiga é a "última fronteira da formação natural da arte e do gosto". ${ }^{27}$ Nomeia esta época a seguir de era dourada, afirmando também que:

A poesia grega como um todo é o máximo e o cânone da poesia natural. [...] Nela está concluído e completado todo o ciclo do desenvolvimento orgânico da arte..$^{28}$

Além disso:

O ápice da formação natural das belas artes permanece então para todos os tempos o arquétipo supremo da progressividade artificial. ${ }^{29}$

Ao enfatizar o caráter cíclico da formação da poesia grega, Schlegel reitera que:

A formação grega era original e nacional, um todo completo em si mesmo, o qual através de seu desenvolvimento interno alcançou um patamar elevado, e num movimento cíclico completo também acabou por se afundar em si mesma. ${ }^{30}$

Schlegel pretende com este texto não só pleitear o estudo e cultivo da poesia grega como corretivos ao estado desolador da poesia moderna, fragmentada,

25 Ver KESTLER. A autonomia estética e o paradigma da Antigüidade clássica no classicismo e na primeira fase do romantismo alemão. Forum Deutsch. Revista brasileira de estudos germânicos, v. 6, p. 77 et seq., 2002.

26 SCHLEGEL. Über das Studium der griechischen Poesie (1795-1797), p. 102.

27 SCHLEGEL. Über das Studium der griechischen Poesie (1795-1797), p. 101.

28 SCHLEGEL. Über das Studium der griechischen Poesie (1795-1797), p. 111.

29 SCHLEGEL. Über das Studium der griechischen Poesie (1795-1797), p. 104.

30 SCHLEGEL. Über das Studium der griechischen Poesie (1795-1797), p. 109. 
sem unicidade, que busca apenas o chocante, o bizarro, o escandaloso e os modismos de toda espécie, mas também indicar à poesia moderna um sentido, um direcionamento. O estudo aprofundado do passado ajudaria na visão de Schlegel, assim, no aperfeiçoamento da poesia moderna. Para ele, é necessário um aperfeiçoamento, porque haveria uma predominância do característico, do individual e do interessante na grande massa da poesia moderna, uma espécie de anarquia estética, que não forma um todo nem uma unidade.

Salta aos olhos que a poesia moderna ou não alcançou ainda o objetivo, ao qual ela almeja, ou que seus esforços não têm nenhum fim determinado, sua formação nenhuma direção, a massa de sua história nenhuma conexão legítima, o todo nenhuma unidade. ${ }^{31}$

E mais adiante:

Falta de caráter parece ser o único caráter da poesia moderna, confusão parece ser a convergência de sua massa, ilegalidade o espírito de sua história, e ceticismo o resultado de sua teoria. ${ }^{32}$

Depois deste diagnóstico aniquilador, Schlegel propõe, como já mencionado acima, o corretivo da poesia grega, cuja história "é a história natural geral da arte poética". ${ }^{33}$ Por outro lado, Schlegel não propõe aqui uma simples imitação da poesia grega, e sim o conhecimento profundo desta poesia:

Somente aquele que a conhece totalmente pode imitá-la. Somente a imita verdadeiramente aquele que se apropria da objetividade da massa completa, do belo espírito de poetas singulares, e do estilo perfeito da era dourada. ${ }^{34}$

Como se vê, Winckelmann não teria feito outro diagnóstico. Mas no meio desta visão desoladora, na qual predominam a anarquia do interessante, o modismo, o feio e o chocante, Schlegel enxerga os primeiros indícios de uma revolução estética, pois

o momento para uma revolução estética parece estar maduro, revolução esta na qual o objetivo da formação estética dos modernos poderia ser dominante. ${ }^{35}$ 
O indício mais forte é a poesia de Goethe, considerada por Schlegel como a aurora da arte autêntica e da poesia pura. Ele estaria numa posição intermediária entre o interessante e o belo, entre o maneirismo e o objetivo. A este sintoma Schlegel acrescenta no campo teórico a luta da filosofia crítica contra o ceticismo, empreendida por Kant e por Fichte, e o empenho acentuado no estudo da poesia grega. A seguir ele propõe quais seriam os pilares desta revolução estética: objetividade, moralidade, busca da harmonia:

Uma legislação estética perfeita seria o primeiro passo da revolução estética. Sua determinação seria dirigir a força cega, harmonizar e equilibrar as disputas, submeter o ilegal à harmonia; conferir à formação estética um fundamento seguro, um rumo visível e um ânimo legal. ${ }^{36}$

Só a teoria é que pode ser o princípio diretor desta formação. Schlegel prossegue sua argumentação historicizando a poesia moderna, cujo desenvolvimento e evolução são determinados pela progressividade infinita:

A história da formação da poesia moderna não representa nada além do que a disputa permanente entre o talento subjetivo e a tendência objetiva da capacidade estética e a predominância paulatina da última. Com cada modificação essencial da relação entre objetivo e subjetivo começa uma nova fase de formação. A poesia moderna já percorreu dois grandes períodos de formação, que não se sucederam como períodos isolados, mas sim penetrando um no outro como elos de uma corrente. ${ }^{37}$

Quais seriam os marcos dessas duas primeiras fases da poesia moderna? O primeiro ciclo estaria determinado pelos "modernos antigos", e teria se iniciado com Dante. A essa fase teria se seguido a segunda, na qual Shakespeare teria sido o início, o apogeu e o fim. Depois deste período teria ocorrido uma estagnação sem par durante mais de 200 anos na poesia européia, a qual estaria em vias de terminar, dando lugar à terceira fase.

Da mesma forma que na obra discutida anteriormente sobre a história moderna, progressiva, e a história grega, cíclica, Schlegel aponta aqui também para a necessidade de uma relação de ação recíproca (Wechselwirkung) entre as duas histórias poéticas, na medida em que a transição para a terceira fase parece estar próxima com a acentuação da objetividade, típica da poesia grega. Ele segue aqui também a idéia já exposta no texto anterior sobre o início da história moderna ainda no bojo da história dos gregos e romanos, e de um fim 
não abrupto, ou melhor, de uma continuidade dialética entre a poesia grega e a moderna.

A formação natural e a formação artificial se encaixam uma na outra, e os últimos da poesia antiga são ao mesmo tempo os precursores da moderna. ${ }^{38}$

Além disso, ele enxerga o renascimento da poesia na terceira fase da literatura moderna "essencialmente como uma reconstituição do espírito objetivo da Antigüidade na época moderna". ${ }^{39}$ Não há na obra de Schlegel uma separação abrupta da Antigüidade e da modernidade, mas sim uma tentativa de conciliação do essencialmente moderno com o essencialmente antigo, que se apresenta inicialmente através da explanação da diferença absoluta entre ambos para então depois se manifestar na necessidade de uma relação recíproca para que se atinja o ideal da poesia, o qual só pode ser alcançado através da aproximação infinita.

Antigüidade e modernidade aparecem aqui numa relação dialética tensa, a qual não ocorreu no tratamento da questão da querela nem na França nem na Inglaterra. A modernidade não se dissocia aqui do clássico, [...] mas sim se coloca numa relação recíproca vital com este. A modernidade ruim, poder-se-ia formular, consiste numa mera separação, num mero progredir, na elevação constante do interessante, num "empenho irrefreável e insaciável pelo novo, o picante, o escandaloso, no qual a ânsia no entanto permanece insatisfeita". A modernidade genuína encontra-se numa relação de igual para igual com o clássico e se manifesta numa disputa, num agon [luta mortal] com ele. ${ }^{40}$

Numa carta a seu irmão August Wilhelm de 27 de fevereiro de 1794, Friedrich Schlegel assim se expressa sobre esta questão:

O problema de nossa poesia me parece ser a fusão do essencialmente moderno com o essencialmente antigo; e se eu acrescentar que Goethe, o primeiro de nosso totalmente novo período da arte, já deu os primeiros passos no sentido de atingir esse objetivo, você irá compreender bem meu ponto de vista. ${ }^{41}$

Schlegel portanto elabora seu Studium-Aufsatz a partir da premissa de uma crise espiritual profunda na Europa e concomitantemente dentro da expectativa de uma revolução estética, a qual já teria se iniciado. É relevante também

38 SCHLEGEL. Über das Studium der griechischen Poesie (1795-1797), p. 64.

39 BEHLER. Einleitung: Friedrich Schlegels Studium-Aufsatz und der Ursprung der romantischen Literaturtheorie, p. 100.

40 BEHLER. Einleitung: Friedrich Schlegels Studium-Aufsatz und der Ursprung der romantischen Literaturtheorie, p. 83-84.

41 Citado segundo: PIKULIK. Frühromantik. Epoche, Werke, Wirkung, p. 149. 
observar que o estilo da argumentação dialética, ou seja, o desdobramento da exposição das idéias em três níveis ou fases no sentido de uma tese, antítese e síntese, utilizado sobejamente nesse texto, foi inspirado pelo tratado de Lessing intitulado Die Erziehung des Menschengeschlechts (A educação do gênero humano), de 1777. Tal estilo de exposição dialética caracteriza também tanto Poesia ingênua e sentimental quanto A educação estética do homem numa série de cartas de Schiller. ${ }^{42}$ No caso específico do tratado de Schlegel, a síntese não significa a resolução final do conflito, mas sim assinala que se trata de uma tarefa infinita, ou melhor, de uma aproximação infinita. Ernst Behler comenta assim o tratado de Schlegel:

Indubitavelmente a temática e a disposição do estudo sobre a poesia grega originamse ainda da primeira fase do idealismo e do antagonismo, característico desta fase, entre liberdade e natureza, homem e mundo, sujeito e objeto. De fato o estudo faz até uma importante contribuição a esta problemática filosófica, quando Schlegel deduz o conceito da formação exatamente destes princípios e determina-o como "relação de ação recíproca da liberdade e da natureza" e mais acentuadamente como "guerra da humanidade e do destino". Além disso, o estudo como um todo pode ser considerado como uma transposição deste antagonismo da liberdade e da natureza ao campo da estética e da teoria literária, na medida em que estes princípios filosóficos fundamentam aqui a poesia natural (natureza) e a poesia artificial (liberdade) e mais ainda na medida em que a elaboração deste antagonismo agudo ou até da oposição absoluta da antigüidade e da modernidade constitui o primeiro passo deste tratado. $\mathrm{Na}$ aproximação dialética de ambos os contrários mostra-se, no entanto, também, que Schlegel na época já estava a caminho de uma filosofia da identidade e operava do ponto de vista da identidade, a partir do qual a oposição cerrada entre natureza e liberdade, classicismo e modernidade se transformou numa cooperação amigável. No fragmento 149 do Athenäum de 1798 dedicado a Winckelmann a "diferença absoluta entre antigüidade e modernidade" é vista apenas como primeiro alicerce de um novo posicionamento estético e sua completude passa a depender de um ponto de identidade, ou seja da "identidade absoluta do antigo e do moderno que existiu, ou existirá". ${ }^{3}$

Em 1797, no entanto, Schlegel critica acidamente seu Studium-Aufsatz na revista Lyceum com as seguintes palavras:

42 HAUPT. Geschichtsperspektive und Griechenverständnis im ästhetischen Programm Schillers. Jahrbuch der Deutschen Schillergesellschaft, p. 418.

43 BEHLER. Einleitung: Friedrich Schlegels Studium-Aufsatz und der Ursprung der romantischen Literaturtheorie, p. 85. O fragmento mencionado é o seguinte: "O sistemático Winckelmann, que, por assim dizer, lia todos os antigos como um único autor, via tudo no todo e concentrava toda a sua força nos gregos, estabeleceu, pela percepção da diferença absoluta entre antigo e moderno, o primeiro fundamento de uma doutrina material da antigüidade. Somente quando forem encontrados o ponto de vista e as condições de identidade absoluta que existiu, existe ou existirá entre antigo e moderno, se poderá dizer que ao menos o contorno da ciência está pronto, e agora se poderá pensar na execução metódica". Citado segundo: SCHLEGEL. O dialeto dos fragmentos, p. 71. 
Meu ensaio sobre a poesia grega é um hino amaneirado, em prosa, àquilo que é objetivo na poesia. A completa falta da indispensável ironia me parece o que nele há de pior; e o melhor, a confiante suposição de que a poesia é infinitamente valiosa, como se isso fosse uma coisa indiscutível. ${ }^{44}$

Apesar dessa autocrítica, o Studium-Aufsatz é de extrema importância no âmbito da construção do ideal romântico-revolucionário que se delineará posteriormente nos anos da primeira fase do Romantismo, sobretudo nos textos publicados nas revistas Athenäum e Lyceum. ${ }^{45}$ A idéia da perfectibilidade como fim inatingível e a concepção da aproximação infinita, formuladas no Studium-Aufsatz, são fundamentais para o entendimento do Romantismo, como se verifica, por exemplo, num dos mais conhecidos fragmentos da revista Athenäum:

A poesia romântica é uma poesia universal progressiva. Sua destinação não é apenas reunificar todos os gêneros separados da poesia e pôr a poesia em contato com a filosofia e a retórica [...] O gênero poético romântico ainda está em devir; sua verdadeira essência é mesmo a de que só pode vir a ser, jamais ser de maneira perfeita e acabada... ${ }^{46}$

Além disso, o Studium-Aufsatz constitui-se, juntamente com o tratado de Schiller, Poesia ingênua e sentimental, publicado em 1795 e 1796 na revista Die Horen (As Horas), num marco fundamental da reflexão estética da modernidade literária.

\section{Referências}

BEHLER, E. ,Die Theorie der Kunst ist ihre Geschichte”: Herder und die Brüder Schlegel. In: BEHLER, E. Studien zur Romantik und zur idealistischen Philosophie. Paderborn: Ferdinand Schöningh, 1993. v. 2.

BEHLER, E. Einleitung: Friedrich Schlegels Studium-Aufsatz und der Ursprung der romantischen Literaturtheorie. In: SCHLEGEL, Friedrich. Über das Studium der griechischen Poesie: 1795-1797. Org. Ernst Behler. Paderborn: Schöningh, 1978. BEHLER, E. Unendliche Perfektibilität. Europäische Romantik und Französische Revolution. Paderborn: Ferdinand Schöningh, 1989.

CONDORCET, Jean-Antonio-Nicolas de Caritat. Esboço de um quadro histórico dos progressos do espírito humano. Campinas: Unicamp, 1993.

44 SCHLEGEL. O dialeto dos fragmentos, p. 21.

45 Vide: HUYSSEN: Republikanismus und ästhetische Revolution beim jungen Friedrich Schlegel, p. 236.

46 SCHLEGEL. O dialeto dos fragmentos, p. 64-65. 
FICHTE, J. G. Lições sobre a vocação do sábio/Reivindicação da liberdade de pensamento. Trad. e apres. Artur Morão. Lisboa: Edições 70, 1999.

FRANK, M. „Unendliche Annäherung”. Die Anfänge der philosophischen Frühromantik. Frankfurt a.M.: Suhrkamp, 1998.

HAUPT, J. Geschichtsperspektive und Griechenverständnis im ästhetischen Programm Schillers. Jahrbuch der Deutschen Schillergesellschaft, $18^{\circ}$ ano, 1974.

HERDER, J. G. Fragmente über die neuere deutsche Literatur. In: HERDER, J. G. Sämtliche Werke. Org. Bernhard Suphan. Hildesheim: Olms-Weidmann, 1967. v. 1. HUYSSEN, A. Nachwort: Republikanismus und ästhetische Revolution beim jungen Friedrich Schlegel. In: SCHLEGEL, Friedrich. Kritische und theoretische Schriften. Seleção e posfácio de Andreas Huyssen. Stuttgart: Reclam, 1978.

KANT, I. Idéia de uma história universal de um ponto de vista cosmopolita. Tradução Rodrigo Naves e Ricardo Terra. São Paulo: Brasiliense, 1986.

KESTLER, I. M. F. A autonomia estética e o paradigma da Antigüidade clássica no classicismo e na primeira fase do romantismo alemão. Forum Deutsch. Revista Brasileira de Estudos Germânicos, v. 6, 2002.

KESTLER, I. M. F. Friedrich Schiller e a fundação do cânone da modernidade. Forum Deutsch. Revista Brasileira de Estudos Germânicos, v. 10, 2006.

KESTLER, I. M. F. Friedrich Schiller X Friedrich Schlegel: confrontos e convergências em torno da fundamentação da modernidade. In: ENCONTRO REGIONAL DA ABRALIC - LITERATURA, ARTES, SABERES, 11., 2007, São Paulo. Anais... São Paulo: ABRALIC, 2007. v. 1. Disponível em: <www.abralic.org.br>.

PIKULIK, L. Frühromantik. Epoche, Werke, Wirkung. Munique: C. H. Beck, 1992.

SCHILLER, F. A educação estética do homem numa série de cartas. Tradução Roberto Schwarz e Márcio Suzuki. São Paulo: Iluminuras, 1995.

SCHILLER, F. Poesia ingênua e sentimental. Tradução e apresentação Márcio Suzuki. São Paulo: Iluminuras, 1991.

SCHLEGEL, F. Herders Briefe zur Beförderung der Humanität (1796). In: SCHLEGEL, F. Kritische Schriften und Fragmente [1794-1797]. Org. Ernst Behler e Hans Eichner. Paderborn: Schöningh, 1988. v. 1.

SCHLEGEL, F. O dialeto dos fragmentos. Tradução, apresentação e notas de Márcio Suzuki. São Paulo: Iluminuras, 1997.

SCHLEGEL, F. Über das Studium der griechischen Poesie (1795-1797). In: SCHLEGEL, F. Kritische Schriften und Fragmente [1794-1797]. Org. Ernst Behler e Hans Eichner. Paderborn: Schöningh, 1988. v. 1.

SCHLEGEL, F. Vom Wert des Studiums der Griechen und Römer (1795-1796). In: SCHLEGEL, F. Kritische Schriften und Fragmente [1794-1797]. Org. Ernst Behler e Hans Eichner. Paderborn: Schöningh, 1988. v. 1.

WINCKELMANN, J. J. Reflexões sobre a arte antiga. 2. ed. Introdução Gerd Bornheim; Tradução Herbert Caro e Leonardo Tochtrop. Porto Alegre: Movimento, 1975. 